\title{
A first method for preparation of biodegradable fibrous scaffolds containing iodine on the fibre surfaces
}

\author{
SEMEN I GORENINSKII ${ }^{1}$, KSENIA S STANKEVICH ${ }^{1,3}$, ANNA L NEMOYKINA ${ }^{2}$, \\ EVGENY N BOLBASOV ${ }^{3}$, SERGEI I TVERDOKHLEBOV ${ }^{3}$ * $\mathbb{D}$ and VICTOR D FILIMONOV ${ }^{1}$ \\ ${ }^{1}$ Department of Biotechnology and Organic Chemistry, National Research Tomsk Polytechnic University, Tomsk 634050, \\ Russian Federation \\ ${ }^{2}$ Biotechnology and Biopolymers Laboratory, Tomsk State University, Tomsk 634050, Russian Federation \\ ${ }^{3}$ Department of Experimental Physics, National Research Tomsk Polytechnic University, Tomsk 634050, \\ Russian Federation \\ *Author for correspondence (tverd@tpu.ru)
}

MS received 29 May 2017; accepted 18 December 2017; published online 24 July 2018

\begin{abstract}
Fibrous electrospun scaffolds made of poly(L-lactic acid) (PLLA) and poly( $\varepsilon$-caprolactone) (PCL) were modified with iodine using 'solvent/non-solvent' treatment of the polymer through two-step process. At the first step, the scaffolds were treated with mixture of toluene and ethanol for pre-swelling of the fibre surfaces. Then, treated scaffolds were exposed to iodine vapours to entrap iodine on the polymer surface. Concentration of iodine in obtained materials was measured by means of UV-spectrophotometry. Morphology of the modified scaffolds was characterized by scanning electron microscopy (SEM). Proposed modification had no significant effect on mechanical properties of the scaffolds and their morphologies. Obtained materials demonstrated the E. coli's antimicrobial activity depending on iodine concentration.
\end{abstract}

Keywords. Biomaterials; polymers; surface modification; antibacterial scaffolds; electrospun scaffolds; iodine.

\section{Introduction}

In the last decades, fibrous scaffolds made of natural or synthetic polymers earned considerable interest as promising materials for regenerative medicine [1,2]. Their fibrous structure maintains essential interactions between cells during tissue formation and regeneration. However, significant problem with application of such implants is possibility of infestation during implantation because of bacteria and viruses adhered on the polymer surfaces [3]. Thus, polymer scaffolds demonstrating antibacterial properties are of great importance. For this purpose, polymer materials were doped with such antibacterial agents as silver, zinc oxide, cerium oxide and antibiotics [4].

Iodine and iodine-containing compounds are well-known in medical practice as an additives demonstrating activity against wide range of bacteria and viruses [5]. X-ray contrast agents [6] and materials for radiotherapy devices (in the case of radioactive iodine isotopes usage) [7]. Various polymer materials containing iodine as a modifying agent are known. For example, material based on polyurethane was obtained by iodine doping during polyurethane polymerization or immersion of polyurethane scaffolds into iodine solution [8]. Developed materials demonstrated antibacterial activity against $S$. aureus. Another iodine-doped polymer, which demonstrated antibacterial activity against E. coli,
P. aeruginosa, S. aureus and K. pneumonia, is nylon [9]. Modification of the nylon sutures was conducted by immersing in iodine solution and acetone. Another advantage of iodine as an antibacterial agent is the possibility of biocompatibility improvement [5]. However, composite materials based on poly( $\varepsilon$-caprolactone) or poly(L-lactic acid) and iodine are still unknown, since iodine is incompatible with these polymers. Addition of $0.05 \mathrm{wt} \%$ concentration of iodine into poly(Llactic acid) films decreased their ultimate tensile strength from $3.44 \pm 0.16$ to $2.94 \pm 0.09 \mathrm{MPa}$. Moreover, such methods as electrospinning and aerodynamic formation are not applicable for processing of such composites due to possible damage of equipment because of the high reactivity of iodine.

Previously, our group proved the possibility of the surface modification of such biodegradable polymers as poly(L-lactic acid) and poly( $\varepsilon$-caprolactone) electrospun-fibrous scaffolds by 'solvent/non-solvent' method [10]. This technique includes treatment of the polymer surface with mixture of solvents followed by exposure into the medium, containing modifying agent [11]. Application of bioresorbable polymer for the scaffold production allows controllable release of the antibacterial agent [12].

In the present study, we report a new method of biodegradable fibrous scaffolds surface modification with iodine and characterization of the obtained materials. 


\section{Experimental}

\subsection{Scaffolds preparation}

Poly(E-caprolactone) (PCL, $\quad M_{\mathrm{w}} \quad 70-90 \quad \mathrm{~kg} \quad \mathrm{~mol}^{-1}$, Sigma-Aldrich, USA) fibrous scaffold was prepared by electrospinning of 9\% (w/w) PCL solution in chloroform using NANON-01A electrospinning setup (MECC Co., Japan). The electrospun scaffolds were collected on a target drum rotating at $50 \mathrm{rpm}$ at a distance of $190 \mathrm{~mm}$ from the syringe tip. The flow rate of the PCL solution was $6 \mathrm{ml} \mathrm{h}^{-1}$ with an applied voltage of $20 \mathrm{kV}$.

Poly(L-lactic acid) scaffolds were prepared by electrospinning of 3\% (w/w) PLLA solution in chloroform with the following parameters: drum rotating at $50 \mathrm{rpm}$, distance from the syringe tip $150 \mathrm{~mm}$, flow rate $6 \mathrm{ml} \mathrm{h}^{-1}$ and the applied voltage of $27 \mathrm{kV}$.

\subsection{Scaffolds modification}

Modification of the PCL and PLLA scaffolds was conducted through two-step process. First, the scaffolds with a size of $20 \times 30 \mathrm{~mm}$ were placed in $10 \mathrm{ml}$ of the mixture of toluene and ethanol $(1 / 9, \mathrm{v} / \mathrm{v})$ for $10 \mathrm{~min}$. Then, treated PCL scaffolds were exposed to iodine vapours for 30, 60, 120, 180, 240 and $300 \mathrm{~s}$ at the room temperature, PLLA scaffolds were again exposed for 30, 60, 180, 240, 300 and $360 \mathrm{~s}$. Excessive iodine was removed by washing the samples with ethanol.

\subsection{Determination of iodine concentration}

Concentration of iodine in the prepared scaffolds was determined by means of UV-spectrophotometry (Specord 250 plus, Analytik Jena AG, Germany). For this purpose, calibration graphs were plotted for the solutions of the scaffolds in dichloromethane with iodine concentrations of $0.001,0.002$, $0.003,0.004,0.005,0.006$ and $0.007 \mathrm{wt} \%$. Iodine concentration in the modified scaffolds was defined according to UV absorption of their solution in $2 \mathrm{ml}$ of dichloromethane at 360 and $500 \mathrm{~nm}$ adsorption maxima.

\subsection{Investigations of iodine desorption kinetics}

Iodine desorption from the modified scaffolds was studied as follows. Material samples containing maximum iodine concentration with the size of $10 \times 10 \mathrm{~mm}$ were placed in $1 \mathrm{ml}$ of normal saline at a temperature of $37^{\circ} \mathrm{C}$. Concentration of the remaining iodine was calculated after $30 \mathrm{~min}$ and 1, 2, 3 and $4 \mathrm{~h}$ of exposure using method described in section 2.3.

\subsection{Mechanical studies}

The mechanical studies were performed using an Instron testing machine (model 3343, USA, load cell $1 \mathrm{kN}$ ). The cross head speed was $5 \mathrm{~mm} \mathrm{~min}^{-1}$. Specimens with a size of $60 \times 20 \mathrm{~mm}$ were prepared. The thickness of the samples was calculated before the test. The gauge between top and bottom clamps was $20 \mathrm{~mm}$.

\subsection{SEM}

Scanning electron microscopy (SEM) of the modified scaffolds was performed using Quanta 200 3D (FEI Company, USA) equipment. Before microscopy, the samples were stored at a low vacuum of $10^{-3} \mathrm{~Pa}$ for 2 days. All the samples were pre-coated with gold using Smart Coater (Jeol, Japan) sputtering system. Microscopy of PCL scaffolds was conducted at a low vacuum, with $\times 3000$ magnification and acceleration voltage of $20 \mathrm{kV}$. For PLLA scaffolds, these parameters were set at $\times 1000$ and $15 \mathrm{kV}$, respectively.

\subsection{Antimicrobial activity studies}

For the study of antibacterial properties of the obtained materials, E. coli B-6954 strain (Russian Collection of Microorganisms) was used. Samples of the modified and nonmodified scaffolds with the sizes of $10 \times 10 \mathrm{~mm}$ were placed in $1 \mathrm{ml}$ of microorganisms suspension in normal saline with concentration of $1 \times 10^{5} \mathrm{CFU} \mathrm{ml}{ }^{-1}$. After $24 \mathrm{~h}$ of cultivation at a temperature of $37^{\circ} \mathrm{C}$, the suspension was diluted with normal saline for 10, 100, 1000, 10000 and 100000 times. One hundred microlitres of each dilution were placed in Petri dishes with beef extract agar and incubated for another $24 \mathrm{~h}$ at a temperature of $37^{\circ} \mathrm{C}$.

\section{Results and discussion}

\subsection{Determination of iodine concentration}

For optimization of the scaffolds modification process, the dynamics of iodine adsorption on the surface of pre-swelled scaffolds were studied. It was found that maximum concentration of iodine in PCL scaffolds was achieved at $180 \mathrm{~s}$ of exposure to iodine vapours and $300 \mathrm{~s}$ for PLLA (figure 1).

Noteworthy, maximum concentration of iodine in modified PCL scaffold was found larger than one for PLLA scaffold. Taking into account that PCL and PLLA have close solubility parameters [13], it may be concluded that molecular mass of the polymer plays main role in observed process. Thus, PCL was swelled better on the first step of the modification process.

Interestingly, iodine amount in obtained samples was decreased after the maximum was achieved. Revealed dynamics contradict with simple adsorption dynamics, according to which saturation of pre-swelled polymer layer with modifying agent was expected. These observations may be explained by the complex action of two processes: during iodine adsorption in pre-swelled polymer layer, the solvents evaporate from the fibre surfaces leading to partial migration and evaporation of iodine from the surface layer. To prove that PCL and PLLA scaffolds treated with mixture of ethanol and toluene 


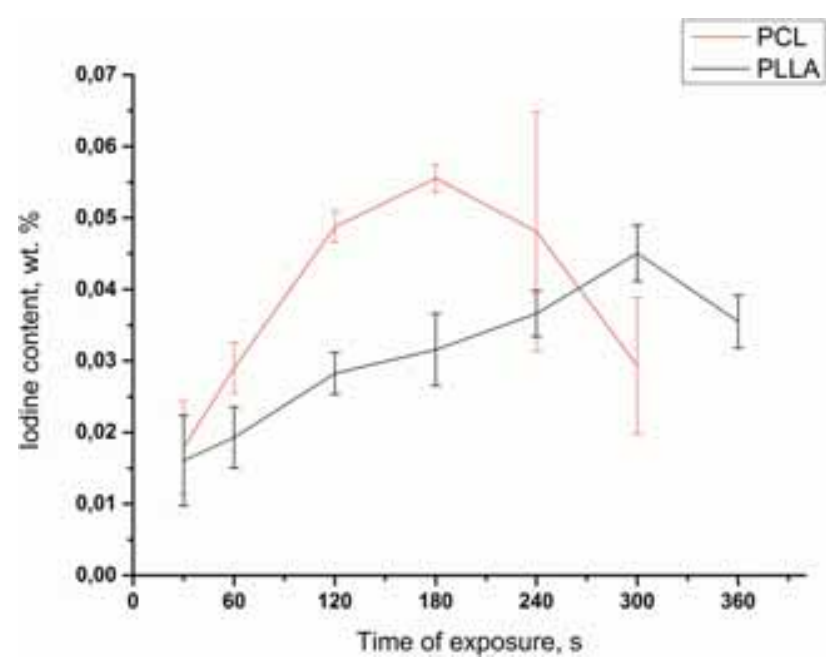

Figure 1. Changes in iodine concentration of modified scaffolds with time on exposure to iodine vapours.

$(1 / 9, v / v)$ for 10 min were placed in the same glass cylinder without iodine vapours for 180 and $300 \mathrm{~s}$, respectively. Then, dried in such manner scaffolds were exposed to iodine vapours. It was found that dried scaffolds lost their ability to adsorb iodine. Thus, solvents evaporation leading to drying of the pre-swelled polymer layers is one of the leading factors limiting iodine adsorption. With reduction of polymer ability to adsorption, iodine can evaporate from the fibre surfaces. Because of the combination of listed effects, iodine amount in obtained materials was decreased.

As the maximum concentrations of iodine were achieved at 180 and $300 \mathrm{~s}$ of exposure to iodine vapours (for PCL and PLLA scaffolds, respectively), materials produced after longer time of exposure were not studied further.

\subsection{Iodine desorption kinetics}

For both polymers, it was found that attached iodine desorbs from the fibre surfaces during first $4 \mathrm{~h}$ of exposure to normal saline. With that, maximum dose of released iodine (more than 40\%) was observed during first $30 \mathrm{~min}$ (figure 2).

Thus, during first $4 \mathrm{~h}$ of the sample exposure to normal saline concentration of iodine sufficient for antibacterial and bacteriostatic effects [14]. It should be noted that desorption behaviour was equal for both the polymers. It is known that release rate of the modifying agent is larger from thicker fibres (in our case, it was PCL fibres) [15]. Moreover, lower molecular mass of PCL also can intensify the release of the drug [16]. However, listed investigations were conducted for filled polymers containing modifying agents in bulk. Most likely, as our materials contain iodine only in surface layers, we observe its 'burst' release taking place from the fibre surfaces.

\subsection{Mechanical studies}

To prove the statement that polymers surface modification has no effects on mechanical properties of the material, ultimate

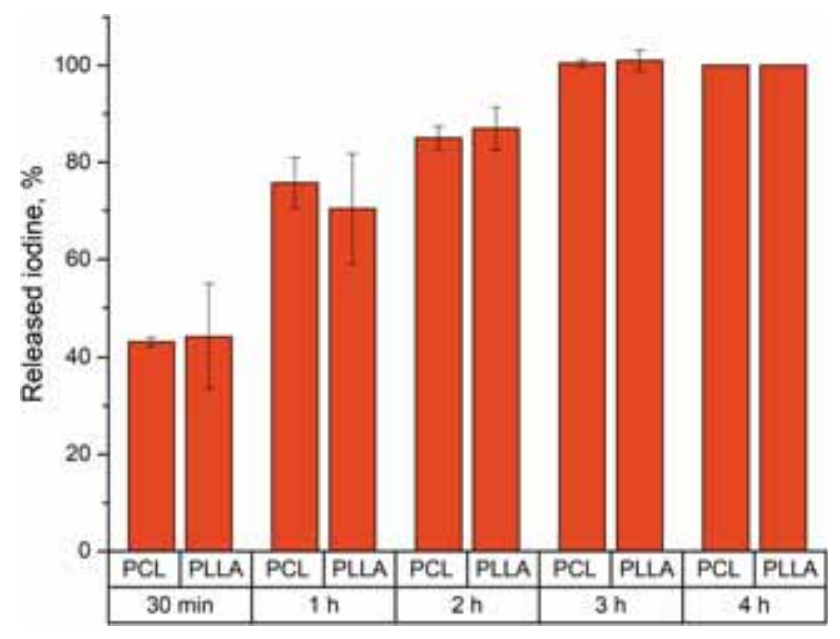

Figure 2. Kinetics of iodine release from modified PCL and PLLA scaffolds.

tensile strength of the non-modified and modified scaffolds were compared (figure 3 ).

Observed changes in ultimate tensile strength of the material were found insignificant and had no obvious dependency from the time of exposure to iodine vapours. Thus, it may be concluded that proposed modification route allows saving mechanical properties of polymer fibrous scaffolds.

\subsection{Scaffolds morphology}

As proposed, modification strategy includes contact of the polymer with organic solvents and such relatively active compounds as iodine, SEM was used to discover its influence on the scaffolds' morphology.

Average diameter of the PLLA fibres was slightly decreased after exposure to iodine vapours (figure 4). Apart from that it may be said that the morphology of the scaffolds was not changed i.e., no glued or broken fibres were found.

Same picture was observed for PCL scaffolds (figure 5). As for PLLA, no significant changes in average fibre diameter were found. Scaffold macrostructure was also not affected. SEM of the obtained materials revealed one more possible cause of higher iodine concentration in PCL scaffolds. As PCL fibres are nearly 2.5 times thicker than PLLA, scaffold surface allowed for iodine adsorption was also increased.

\subsection{Antibacterial activity}

It was observed that obtained materials demonstrate antibacterial properties against E. coli. Significant reduction of bacterial count was observed during the incubation with unmodified scaffold. It was suggested that fibrous structure of the material keeps a part of bacteria inside the material and further reduces bacterial count due to iodine antimicrobial activity. 

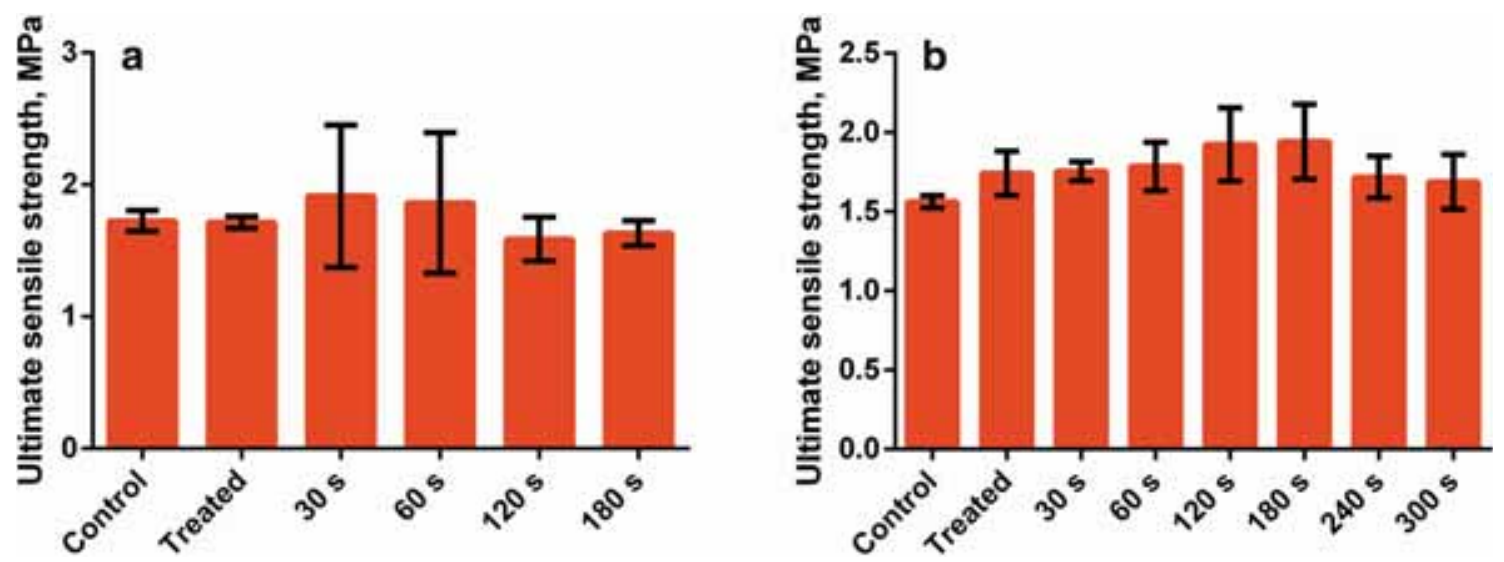

Figure 3. Ultimate tensile strengths of control and modified scaffolds: (a) PLLA scaffolds and (b) PCL scaffolds.
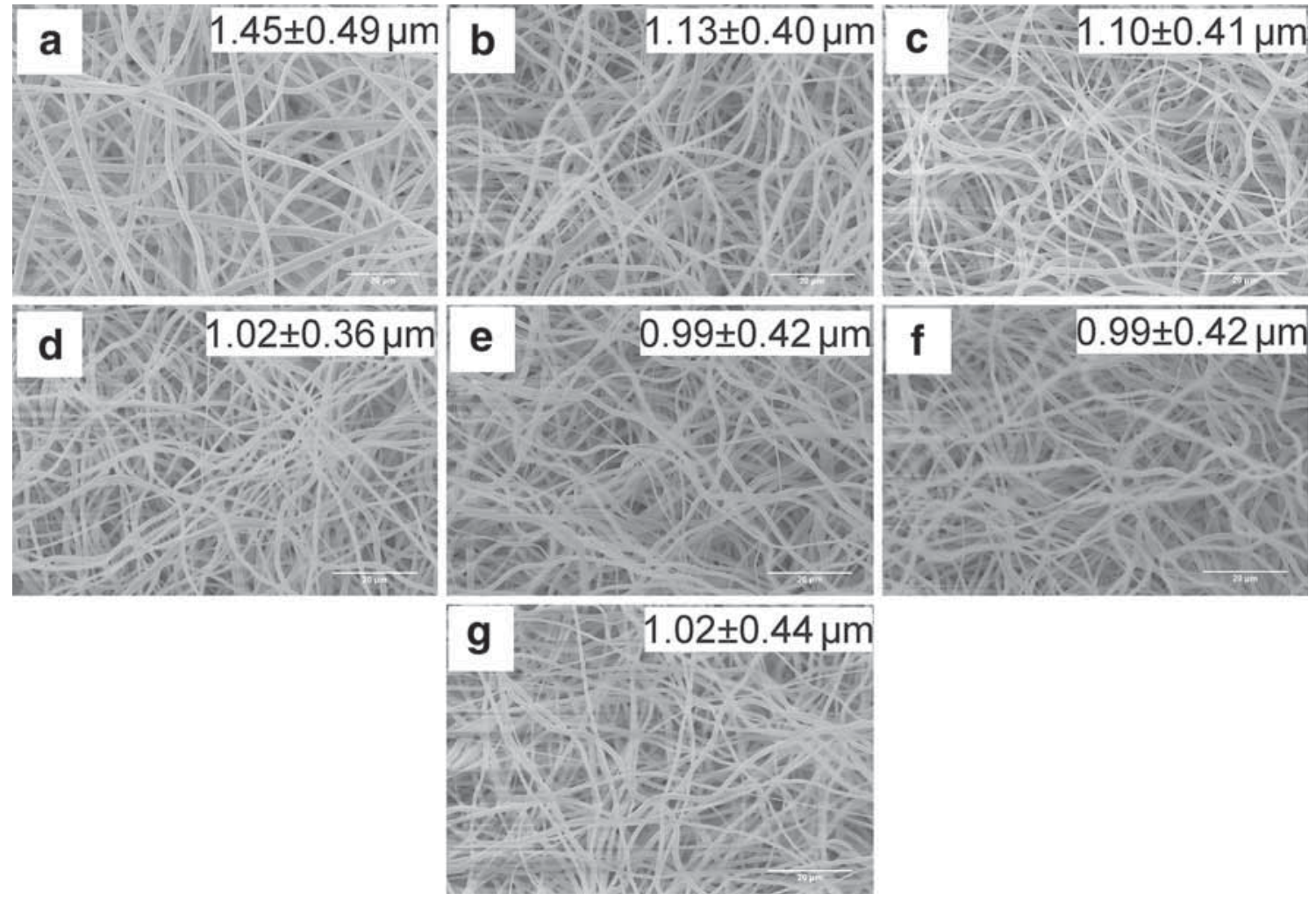

Figure 4. SEM images of modified and non-modified PLLA scaffolds: (a) non-modified scaffold; (b-g) PLLA scaffolds treated with 'solvent/non-solvent' mixture and exposed to iodine vapours for 30, 60, 120, 180, 240 and 300 s, respectively. Average fibre diameter is given in the top right corner.

PCL scaffolds exposed to iodine vapours for $180 \mathrm{~s}$ demonstrated $100 \%$ efficacy against $E$. coli in $24 \mathrm{~h}$ (figure 6). In comparison with some reported fibrous polymer structures demonstrating antibacterial properties (such as PLLA and PCL scaffolds containing silver nanoparticles [17] or gum tragacanth [18]), scaffolds described in the present work are more effective.

Antibacterial activity was also observed for modified PLLA scaffolds (figure 7). As for PCL scaffolds, significant decrease in bacteria concentration was revealed after cultivation with non-modified scaffold. Modification of the PLLA scaffolds by described route allowed sustaining bacteria concentration at the level of $(1.2 \pm 0.5) \times 10^{5} \mathrm{CFU} \mathrm{ml}^{-1}$. Thus, from the point of antibacterial properties, modified PCL scaffolds are more preferable owing to higher iodine concentration and lower molecular mass that results in more sufficient iodine adsorption and contact of the attached iodine with surrounding media. 

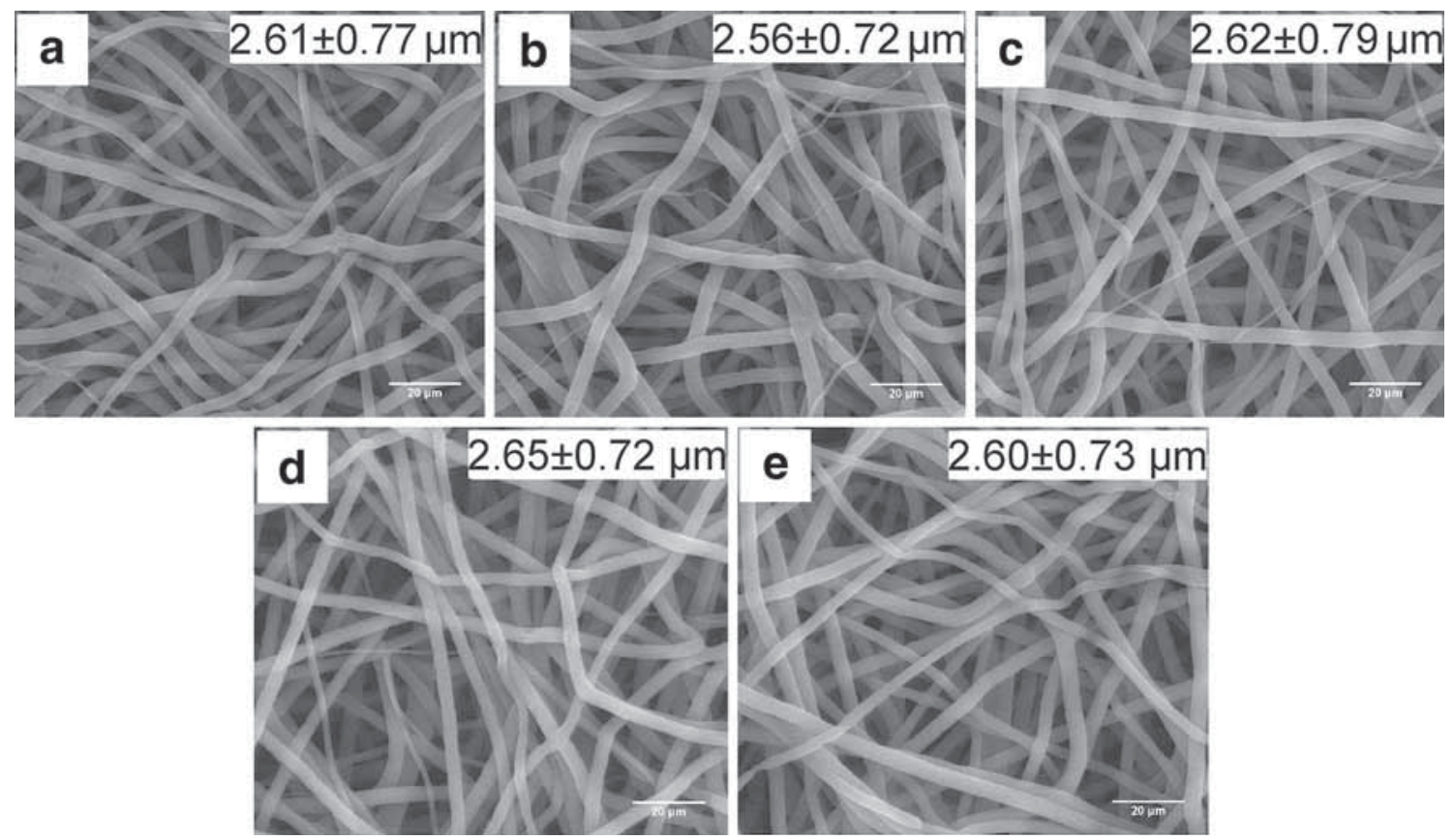

Figure 5. SEM images of modified and non-modified PCL scaffolds: (a) non-modified scaffold; (b-e) PCL scaffolds treated with 'solvent/non-solvent' mixture and exposed to iodine vapours for 30, 60, 120 and $180 \mathrm{~s}$, respectively. Average fibre diameter is given in the top right corner.

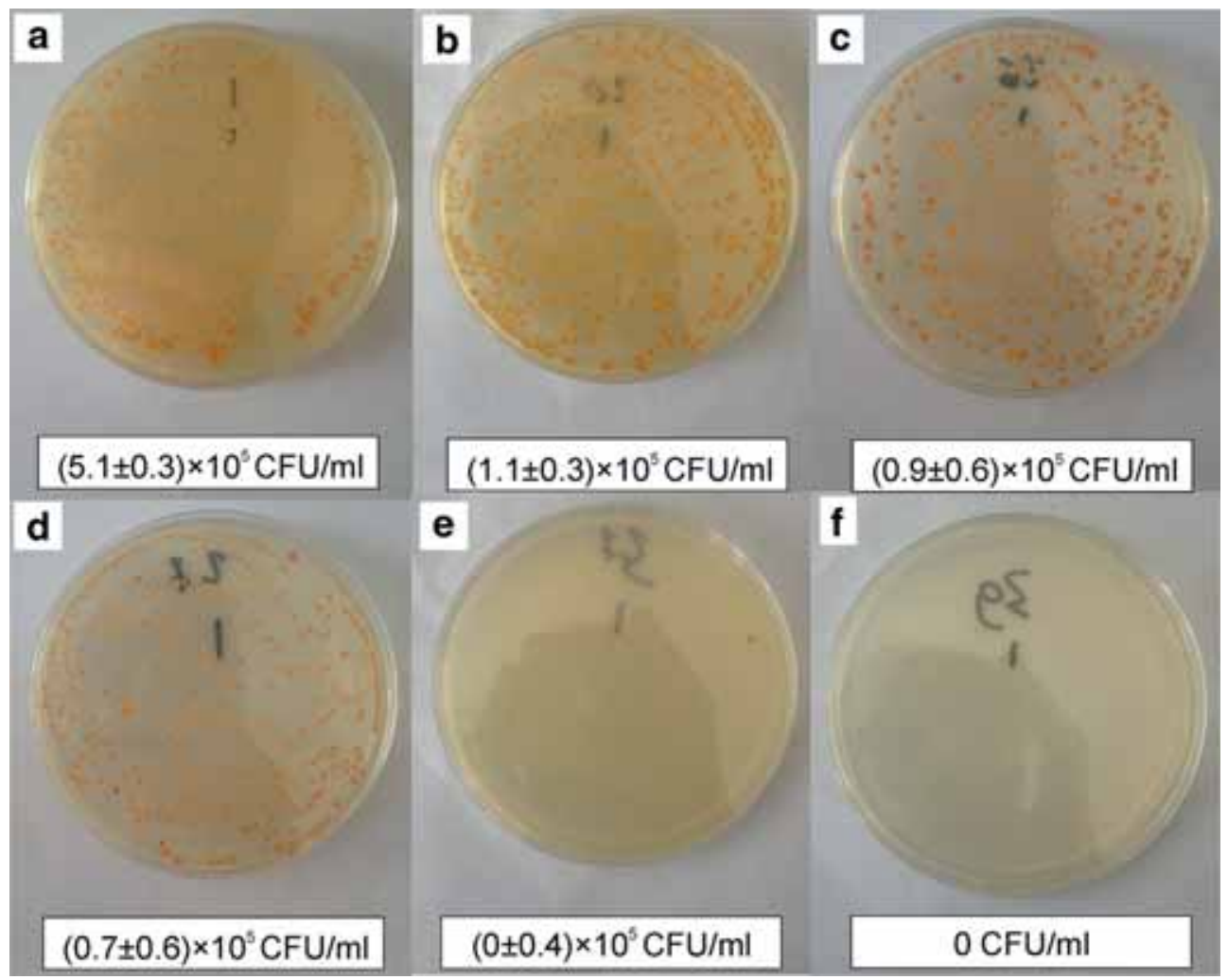

Figure 6. Plates of E. coli colonization after $24 \mathrm{~h}$ of cultivation: (a) microorganisms suspension with concentration of $10^{5}$; (b) after cultivation with non-modified PCL scaffold; (c-f) after cultivation with PCL scaffolds exposed to iodine vapours for 30,60, 120 and 180 s, respectively. 


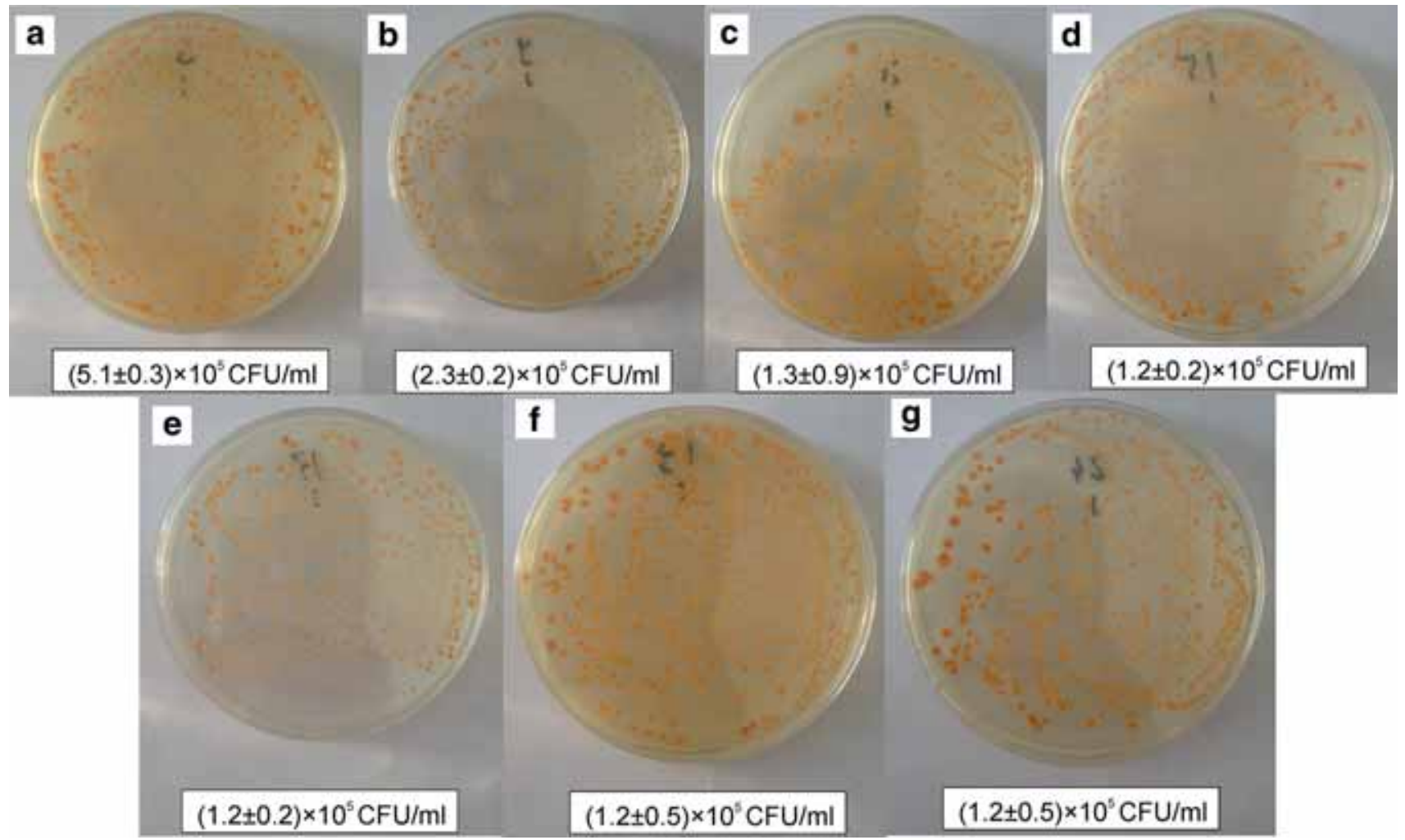

Figure 7. Plates of E. coli colonization after $24 \mathrm{~h}$ of cultivation: (a) microorganisms suspension with concentration of $10^{5}$; (b) after cultivation with non-modified PLLA scaffold; (c-g) after cultivation with PLLA scaffolds exposed to iodine vapours for 30, 60, 120, 180, 240 and 300 s, respectively.

\section{Conclusion}

Iodine attachment method based on 'solvent/non-solvent' technique was applied for modification of biodegradable scaffolds made of PLLA and PCL for the first time. Presented method consists of two steps. First, polymer scaffolds were treated with mixture of toluene and ethanol to obtain preswelled layer on the fibre surfaces. Then, treated scaffolds were exposed to iodine vapours. In the present study, achieved concentrations of iodine are at 0.055 and $0.045 \mathrm{wt} \%$ for PCL and PLLA scaffolds, respectively. It was suggested that in the case of polymer modification through 'solvent/non-solvent' treatment, the main limiting factor is polymer molecular mass. Characterization of the modified scaffolds showed no negative effects on mechanical properties and changes in morphology of the material. Owing to antibacterial activity of the obtained materials, one of the most promising applications is wounddressing material.

\section{Acknowledgements}

This research was supported by Tomsk Polytechnic University Competitiveness Enhancement Program Project VIU-SEC B.P. Veinberg-210/2018.

\section{References}

[1] Barnes C P, Sell S A, Boland E D, Simpson D G and Bowlin G L 2007 Adv. Drug Deliv. Rev. 591413

[2] Kosuge D, Khan W S, Haddad B and Marsh D 2013 Curr. Stem Cell Res. Ther. 8185

[3] Gristina A G 1987 Science 2371588

[4] Muñoz-Bonilla A and Fernández-García M 2012 Prog. Polym. Sci. 37281

[5] Shirai T, Shimizu T, Ohtani K, Zen Y, Takaya M and Tsuchiya H 2011 Acta Biomater. 71928

[6] Novakova K, Laznicek M, Rypacek F and Machova L 2002 J. Bioact. Compat. Polym. 17285

[7] Abboud F, Hollows M, Scalliet P and Vynckier S 2010 Med. Phys. 372054

[8] Touitou E, Deutsch J and Matar S 1994 Int. J. Pharm. 103199

[9] Singhal J P, Singh J, Ray A R and Singh H 1991 Biomater. Artif. Cells Immobilization Biotechnol. 19631

[10] Goreninskii S, Stankevich K, Bolbasov E, Danilenko N, Filimonov V and Tverdokhlebov S 2016 MATEC Web Conf. 79 1025

[11] Stankevich K S, Gudima A, Filimonov V D, Klüter H, Mamontova E M, Tverdokhlebov S I et al 2015 Mater. Sci. Eng. C 51 117

[12] Agarwal S 2012 Polymer science: a comprehensive reference (Elsevier Science) vol 5 p 333 
[13] Adamska K, Voelkel A and Berlińska A 2016 J. Pharm. Biomed. Anal. 127202

[14] Shih Lu Chang and Carrell Morris J 1953 Ind. Eng. Chem. 45 1009

[15] Petlin D G, Amarah A A, Tverdokhlebov S I and Anissimov Y G 2017 J. Control Rel. 258218
[16] Cantin O, Siepmann F, Danede F, Willart J F, Karrout Y and Siepmann J 2016 J. Drug Deliv. Sci. Technol. 36130

[17] Xu X, Yang Q, Wang Y, Yu H, Chen X and Jing X 2006 Eur. Polym. J. 422081

[18] Zarekhalili Z, Bahrami S H, Ranjbar-Mohammadi M and Milan P B 2017 Int. J. Biol. Macromol. 94679 